\title{
Discourse Markers in Writing on Facebook BY EARLY Balanced ENgLish/ITALIAN BILINGUALS
}

\begin{abstract}
This article presents a case study concerning the use of discourse markers (further - 'DMs') in the writing of status updates on Facebook by a group of early balanced English/Italian bilinguals (further - 'participants'), who were born in Australia in the families of Italian immigrants. The corpus of the participants' status updates on Facebook was analysed by means of the WordSmith software for linguistic analysis (Scott 2008) in order to identify the frequency of DMs used by the participants in the English and Italian languages, respectively. The results of the data analysis indicated that the participants employed, predominantly, English DMs (for instance, and, but, though, and yep), while the repertoire of the Italian DMs was limited to diciamo (English equivalents, e.g. let's say, I mean), ecco (English equivalents, e.g. here, well), and ma (English equivalents, e.g., but, yet). These findings are further presented and discussed in the article.
\end{abstract}

\section{Keywords}

English/Italian early bilinguals; discourse markers; bilingual writing; written discourse on social media sites

\section{Introduction}

This article focuses on a case study aimed at exploring how early balanced English/ Italian bilinguals use discourse markers (further referred to as 'DMs') in writing on Facebook, a social medium platform. The case study is informed by the following notions, i) DMs, ii) early balanced bilingualism, and iii) bilinguals' written discourse on social networking sites. In the introductory part, I will provide an overview of 
DMs and early balanced bilingualism, respectively, whereas bilinguals' written discourse on social networking sites will be outlined in section 1.3 of the article.

DMs are regarded as linguistic elements that "signal relations between units of talk by virtue of their syntactic and semantic properties and by virtue of their sequential relations as initial or terminal brackets demarcating discourse units" (Schiffrin 1987: 40). By explaining this definition, Heine (2013: 1208) argues that in the English language DMs are illustrated by such words and phrases as anyway, however, indeed, I mean, you know, you see, etc. The literature in linguistics (Bazzanella et al. 2007; Orsolini 1993; Waltereit 2002) indicates that typical examples of DMs in Italian are allora (translated into English as "then", "therefore"), diciamo ("let's say"), and insomma ("in conclusion", "finally"). In the present case study, DMs are considered to be utterance-initial elements whose use is syntactically independent and sequentially dependent (Maschler and Schiffrin 2015; Schiffrin 1987).

As noted by Maschler (2000: 437), bilingual discourse provides unique perspectives on DMs, since the use of DMs by bilinguals involves code-switching, code-mixing, and pragmatic transfer of DMs from the bilinguals' L1 into their L2 (Hlavac 2006: 1870). In terms of the acquisition of DMs by bilinguals, Fox Tree (2010: 273) claims that "the meaning of discourse markers has to be learned, both in first and second language acquisition." This statement echoes Sankoff et al.'s (1997) claim, emphasising that DMs are "of particular interest because they constitute an aspect of the language not taught in school" (Sankoff et al. 1997: 193). While bilingual children's repertoire of DMs is limited, it may grow concurrently with an increase of the bilinguals' proficiency in their two languages. According to Matras (2000), a repertoire of DM enjoyed by bilingual individuals may expand due to the use of DMs from their primary language in their secondary language and vice versa (Matras 2000). Arguably, there is a possibility of crossfertilisation of the bilingual's repertoire of DMs by means of accessing the DMs stored in the bilingual's lexicon.

Certain DMs in the bilingual's lexicon are liable to pragmatic transfer between the bilingual's languages (Hlavac 2006). Pragmatic variables are thought to be involved in the use of DMs (Matras 2000). Specifically, prior research indicates that DMs are used in accordance with pragmatic purposes and genre conventions that are expected in a given communicative situation (Matras 2000). To illustrate the point, Fox Tree (2000) indicates that a number of DMs (for instance, I mean, you know, you see) are typically associated with unprepared speech, or with spontaneous writing in chatting and messaging online (Fox Tree 2015).

Recently, we have witnessed a growing research attention to the use of DMs by bilinguals (Goss and Salmons 2000; Paculanang 2018; Trillo 2002). Traditionally, the term 'bilingual' is thought to refer to individuals, who use two languages in their everyday lives (Grosjean 1994) "for different purposes, in different domains of life, with different people" (Grosjean 2010: 29). Within the context of this case study, bilinguals are regarded as individuals, who know "the second language to such an extent that he/she is able to communicate in this language freely, both 
in speaking and writing, irrespective of the context of acquisition" (Majchrzak 2017: 9). Whilst the present study does not aim at providing an exhaustive theoretic account of bilingualism (see Cieślicka 2015 for a meta-analysis of the stateof-the-art theoretical premises of bilingualism), it, nevertheless, deals with the notion of an "early balanced bilingual".

Early balanced bilinguals are those bilingual individuals, who perform equally well in both languages (Meisel 2007: 496). Research in linguistics, psycholinguistics, and psychology shows that early balanced bilingualism involves a host of variables (Dunn and Fox Tree 2009; Foursha-Stevenson and Nikoladis 2011; Heredia and Cieślicka 2014). One of the variables is associated with the bilinguals' personal language histories that are reflective of the age of their second language (L2) acquisition. Other variables involve, for instance, the bilinguals' dominant language, and the use of their languages (Nikoladis 2006; Van der Linden et al. 2018; Wang 2013; Yow and Li 2015). Heredia and Cieślicka (2014: 22) point out that based upon the age of L2 acquisition, "it would also be possible to fine-tune the early bilingual distinction into early child, late child, and early adult bilingualism, respectively". Specifically, Heredia and Cieślicka (2014) distinguish between "early bilinguals, whose L2 is learned early in life (i.e., early childhood), and late bilinguals, whose L2 is learned late in life (i.e., after childhood)" (Heredia and Cieślicka 2014: 22).

As far as the use of the early balanced bilinguals' languages in writing is concerned, previous research focuses on bilinguals' offline writing in their two languages (Francis 2005; Torres 2002). In contrast, little attention has been awarded to online writing by early balanced bilinguals (Yang, Yang, and Hartanto, 2019). The present case study seeks to provide new insights into the use of DMs in online writing by a group of English/Italian early balanced bilinguals (henceforth - 'participants'), who acquired their two languages before the age of five. In particular, the case study aims to establish how the participants use DMs in the writing of their status updates on the social platform Facebook.

The article begins with an overview of previous research associated with the use of DMs by bilingual speakers (section 1.1). This is followed by an outline of previous research involving writing by bilinguals (section 1.2). Thereafter, in section 1.3. I will provide an overview of previous studies associated with written discourse on social networking sites. Having introduced the background notions and literature review (sections 1.1-1.3), I will present this study, its corpus and methodology in sections 2-2.4. The results and discussion of the results in the present study will be outlined in section 2.5 . The article concludes with a summary of the findings (section 3).

\subsection{An Outline of Previous Research Associated with the Use of DMs by Bilinguals}

DMs in bilingual discourse have received scholarly attention in linguistics and psycholinguistics. There are papers comparing DMs in such language combinations 
as Cebuano/English (Paculanang 2018), English/Croatian (Hlavac 2006), English/French (Sankoff et al. 1997), English/German (Fuller 2001), Hebrew/English (Maschler 2000), and Spanish/English (Andersen et al. 1999; Flores-Ferrán 2014; Torres 2002). These studies are based, predominantly, upon oral bilingual data that are analysed from different perspectives, e.g. longitudinal (Andersen et al. 1999; Maschler 2000), pragma-communicative (Flores-Ferrán 2014; Fuller 2001; Hlavac 2006; Sankoff et al. 1997; Torres 2002), and psycholinguistic (Paculanang 2018).

The longitudinal perspective on the use of DMs by Spanish/English bilinguals residing in USA is investigated by Andersen et al. (1999). They have found that while the use of DMs is not significant among the youngest children, there is an increase of DMs that is concurrent with age. Specifically, by the age of six and/ or seven, bilingual Spanish/English children demonstrate variation in their use of DMs. Andersen et al. (1999) argue that pre-school bilingual children exhibit awareness of the pragma-discursive context of the DMs use. In a longitudinal study, Maschler (2000) investigates how English/Hebrew bilinguals use DMs in their everyday communication in Israel. Maschler (2000) found that two English/Hebrew bilinguals increased their use of Hebrew DMs over time. The increase of Hebrew DMs is observed in the bilinguals' writing (Maschler 2000: 556). Maschler (2000) indicates that the increase in L2 proficiency contributes to a polyphony of discursive voices associated with the use of DMs by Hebrew/ English bilinguals. In this regard, Maschler (2000) suggests that the bilingual Hebrew/English interlocutors use DMs in order to construct either a voice of another person in oral discourse or to correct the voice of the speaker.

From a pragma-communicative perspective, Fuller (2001) explores a pragmatic dimension of the use of DMs by English/German bilinguals in the US. She found that the borrowing of DMs from German into English by the bilinguals is pragmatically motivated. In particular, the presence of both German and English DMs in the bilinguals' speech signals convergence in the contact situation involving these two languages. Fuller's (2001) findings lend support to the hypothesis involving pragmatic detachability as a motivation for borrowing of DMs. Similarly to Fuller (2001), Torres (2002) examines a bilingual situation in USA, where the focus of the investigation is on the linguistic contact of English and Spanish DMs in oral discourse by New York Puerto Ricans. She argues that DMs are prone to borrowing (2002: 66). Torres (2002) identifies English DMs that are present in the bilinguals' oral discourse in the Spanish language irrespective of language dominance. She concludes that the borrowing of English DMs takes place in synchrony in the cohort of bilingual Puerto Ricans residing in New York. Torres (2002: 78) observes that the New York Puerto Rican bilinguals retain the use of Spanish DMs in their speech. Analogous results are reported by Flores-Ferrán (2014), who investigates DMs in Spanish/English bilingual speech production by New York City-born Puerto Ricans and Puerto Rico Islanders. Her findings reveal that those Spanish/English bilinguals who were born in the US prefer the use of Spanish DMs. Moreover, they exhibit a restricted pragmatic use of DMs (Flores-Ferrán 2014: 57). 
The pragma-communicative perspective is present in the studies that were carried out by Hlavac (2006), and Sankoff et al. (1997), respectively. Hlavac (2006) investigates the use of DMs by the second generation Australians who are speakers of Croatian and English. Specifically, the study examines the frequency and functionality of English DMs in comparison to Croatian DMs in speech recordings of 100 Croatian/English bilinguals. Hlavac (2006) found that English DMs tend to generally co-occur with Croatian DMs. However, Croatian DMs are displaced by English DMs when they are polyfunctional. For instance, younger Croatian/ English bilinguals exhibit a tendency to use a statistically significant number of English DMs, for example, yeah, in their speech in Croatian. Similarly to Hlavac (2006), Sankoff et al. (1997) analyse the use of DMs by Anglophone speakers of French in Montreal (Canada) from the pragma-communicative perspective. They found that oral discourse by late English/French bilinguals is characterised by a significant variation of the use of DMs. The frequent use of French DMs has been identified in speech production by those bilinguals, who possess substantial knowledge of French grammar. Their finding shows that a higher frequency of DMs is an index of the bilingual's speech fluency in French L2.

A psycholinguistic perspective is employed by Paculanang (2018), who investigates the use of DMs by Cebuano/English bilinguals. Paculanang (2018) investigates the role of anxiety in the classroom speech by bilingual teacher trainees, whose weaker language is English. She observes that the teacher trainees' anxiety maps onto the instances of code-mixing that involve Cebuano, a language spoken on the Philippines. Interestingly, she notes that code-mixing in English is associated with the use of Cebuano DMs, when the bilinguals experience anxiety in their classroom speech.

\subsection{An Overview of Background Notions Associated with Writing by Bilinguals}

As observed by Ardila et al. (2017:387), "written bilingualism represents a particular type of bilingualism that is not frequently approached". I agree with Gort (2006: 324), who argues that "a review of published literature revealed little research on early bilingual writing development...". A similar view is shared by Bongartz and Torregrossa (2017: 1), who suggest that while there are cognitive and linguistic benefits of balanced bilingualism, "the research on balanced biliteracy is still in its initial stages". Studies of early balanced bilinguals' writing are still rare.

Writing is a process that involves a cognitively taxing set of components. This article follows the model of writing proposed by Chenoweth and Hayes (2001), which, arguably, appears to be applicable to mono- and bilingual writing. The model consists of the following components: the Proposer, the Translator, the Transcriber, and the Reviser (Chenoweth \& Hayes 2001), where

The Proposer is associated with conceptual processes such as generating and organizing content. The Translator is associated with linguistic processes, such 
as lexical access and syntactic frame construction, which convert concepts into language. The Transcriber turns the language generated by the Translator into written form. The Reviser evaluates both proposed language that has not yet been transcribed and transcribed language, identifies problems and inadequacies, and, if deemed necessary, initiates changes. The component processes of writing require online management and coordination at different levels. (Stevenson, Schoonen and de Glopper 2006: 202)

Paraphrasing Francis (2006: 77), the components in this model, that is, the Proposer, the Translator, the Transcriber, and the Reviser may be affected by the bilinguals' language-specific knowledge, language-specific abilities, individual characteristics, non-linguistic knowledge and skills, and "the ability to decode and encode meaning in the written texts in two languages" (de la Luz Reyes 2012: 249). Presumably, to be able to perform a written task, an early balanced bilingual should possess a substantial degree of the executive control in every of the above-mentioned components. According to Yow and Li (2015: 1), executive control is defined as a "set of skills required for cognitive processes such as inhibition, switching attention, and working memory". Previous research in psychology provides evidence of the bilinguals' inhibition of non-relevant information, which is "consistent with the notion that bilinguals recruit the executive control system in order to manage the simultaneous activation of their two languages" (Tao et al. 2011: 1). The notion of inhibition is of particular relevance to the process of writing by bilinguals. In the light of Green's (1998) Inhibitory Control Model, bilinguals need to inhibit the activation of their another language while producing written output in the target language.

Assuming that inhibition is compromised due to one of the numerous variables, such as, for instance, attention, insufficient writing skills, and/or working memory constraints, a piece of writing by an early balanced bilingual might, potentially, be associated with instances of code-switching and/or code-mixing. According to Olshtain and Blum-Kulka (1989: 60-61), code-switching involves instances when a bilingual alternates grammatical clauses or sentences, whilst in code-mixing words or idiomatic expressions from one language are inserted into the sentence written in another language. The afore-mentioned definition is further specified by MacSwann (2008), who argues that in code-switching "alternation occurs below sentential boundaries, is known as intrasentential codeswitching, whereas switching between sentences is known as intersentential code-switching" (MacSwann 2008: 323).

It should be noted that bilinguals "often code-switch from one language to another, especially when both languages are used in the environment" (Heredia and Altarriba 2001: 164). Goss and Salmons (2000: 470) indicate that a common result of bilingual situations, or the bilingual environment in the sense expressed by Heredia and Altarriba (2001), is interference in DMs, or in other words, codemixing as far as the use of DMs is concerned. In this regard, Dailey-O'Cain and Liebscher (2006) suggest that there is a dynamic continuum involving code- 
switching and code-mixing as far as the use of DMs is concerned. This continuum may encompass the borrowing of DMs from one language to another, the insertions of DMs from the bilingual's language into another, and, possibly, novel coinages of DMs in bilingual discourse. Presumably, code-switching and/ or code-mixing would be represented in the bilinguals' writing on social networking sites, since this type of discourse is typically characterised as facilitative of codeswitching (Reershemius 2017). This assumption is echoed by Androutsopoulos (2015), who argues that computer-mediated communication (CMC) and, in particular, social networking sites are a rich arena of multilingualism and code-switching (Androutsopoulos 2015: 187). In the next section, I will provide an overview of previous studies associated with written discourse on social networking sites.

\subsection{An Overview of Previous Research Associated with Written Discourse Pro- duced by Bilinguals on Social Networking Sites}

Prior studies associated with written discourse on social networking sites (SNS) are widely represented (Androutsopoulos 2014; Blommaert, Collins and Slembrouck 2005; Christiansen 2018; Pérez-Sabater and Moffo 2019; Riley 2015). SNS are typically regarded

as offering users a public or semi-public profile within a bounded system; an articulated list of other users with whom the user shares an interest, and the ability to traverse the list of connections made by themselves and others within the system (Page 2010: 425)

Recent research literature indicates that written discourse on SNS involves such variables as i) semiotic materiality, ii) access to online media networks, and iii) a networked audience (Androutsopoulos 2015). Written discourse on SNS is theorised to be concomitant with variability in both linguistic form and in terms of pragmatic functions that are associated with the creation of online social identities and relationships with the networked audience (Androutsopoulos 2014). Writing on SNS often includes multimodal modes of expression, such as music, photos, YouTube videos, hyperlinks to the Internet resources, streaming services, etc. (Androutsopoulos 2014; Blommaert, Collins and Slembrouck 2005).

Whereas the literature suggests that writing on SNS is characterised by variability due to the varied resources and the writer's identity (Androutsopoulos 2014; Blommaert, Collins and Slembrouck 2005), recent studies argue that variability appears to be a frequent phenomenon in online writing by bilinguals (Christiansen 2018; Pérez-Sabater \& Moffo 2019; Riley 2015), who code-switch while online. Written discourse on SNS involves such variable as a bi- and multilingual public audience that is characterised by a varied social distance to the bilingual writer (Androutsopoulos 2015). In particular, an online bilingual writer's public audience on such SNS as Facebook may involve family, close friends, 
acquaintances, work colleagues, people who follow the writer on Facebook (followers), and any user of Facebook provided they have access to the public updates and/or public posts by the Facebook writer (Christiansen 2018; Pérez-Sabater and Moffo 2019; Riley 2015). Presumably, the variation in the audience as well as the social distance within the members of the social networks map onto a bilingual writer's choice of the linguistic code while writing on SNS. In this regard, Riley (2015) argues that when writing online, bilinguals do not seem to arbitrary switch from one language to the other. Instead, they exhibit awareness and control of the reasons that prompt their choice of the language (Riley 2015).

There is a burgeoning line of research that explores written discourse produced by bilinguals on SNS, in particular, on Facebook (Christiansen 2018; Pérez-Sabater and Moffo 2019; Riley 2015). Arguably, there are several research themes that provide a common denominator for the studies conducted between 2015 and 2019. These themes are the bilinguals' online identity and language mixing strategies (often referred to in the literature as 'translanguaging'), respectively. In a recent study, Pérez-Sabater and Moffo (2019) examine language choice and code-switching on Facebook pages by bilingual football fans in Cameroon and Spain, respectively. Pérez-Sabater and Moffo (2019) indicate that code-switching in the form of translingual written exchanges is frequently adopted by the participants in the study. They argue that code-switching serves to establish identities and create in-group language styles.

Written discourse on Facebook by English/Spanish bilinguals is investigated by Christiansen (2018), who contrasts US-born and Mexico-born bilinguals' writing on Facebook in order to establish how bilinguals construe and view their identity depending on whether they communicate in Spanish or English. Christiansen (2018) argues that Facebook offers an empowering discursive space for the bilinguals in her study. Specifically, she has found that when US-born and English dominant bilinguals interact among themselves in Spanish on Facebook, they tend not to code-mix and use the standard variety of the Spanish language. However, when the same US-born bilinguals interact in Spanish with their Mexican counterparts, their use of Spanish regardless of proficiency is not credited by the Mexican-born bilinguals.

Similarly to Christiansen (2018), Riley (2015) explores written discourse on Facebook produced by a group of Mexican-born English/Spanish bilinguals. The focus in her study is on cognitive processes involved in the bilinguals' writing of Facebook status updates in English and Spanish, respectively. The findings in the study suggest that regardless of the language, the bilinguals make a series of decisions as they select the content, choose the language, formulate the text and type the status updates (Riley 2015: 11-12). The findings lead Riley (2015) to suggest that the bilinguals' higher language proficiencies result in increased automaticity of writing on the social media platform Facebook. It should be noted that the study by Riley (2015) addresses the process of the bilinguals' writing on Facebook and not the Facebook status updates as a final product of writing. 


\section{The Present Study}

Whereas the use of "DMs plays a fundamental role in spoken interaction" (Fung and Carter 2007: 410), analyses of the use of DMs in written discourse produced by bilinguals are still rare. The present study focuses on DMs in written discourse on SNS produced by a group of early balanced English/Italian bilinguals residing in Australia. In the study, attention will be paid to the frequencies of DMs in a corpus of writing by English/Italian bilinguals on the SNS Facebook. The DMs are investigated as a product of writing and not as a process of writing.

It has been assumed in this study that the writing of status updates on Facebook would be reflective of the participants' spontaneous writing. The assumption was tested in a pilot questionnaire distributed to the participants in order to explore whether or not they would typically write their Facebook status updates spontaneously or with prior preparation that, for instance, might involve editing before posting on Facebook. It is evident from the pilot questionnaire that, while the participants write spontaneously on Facebook in the majority of instances, they, nevertheless, post edited status updates at irregular intervals that are mostly related to either political, volunteer, and/or professional activities. Hence, we refer to the participants' writing of status updates on Facebook not as a case of spontaneous writing, but rather online writing.

Our hypothesis is based upon a contention that early balanced bilinguals should possess a substantial degree of executive control involving inhibition, attention switching, and working memory in order to perform a written task in a multimodal environment afforded by Facebook (Riley 2015). Given that previous research provides evidence of the bilinguals' inhibition mechanism (Green 1998), bilinguals need to inhibit the activation of their another language while producing written output in the target language. Hence, it is assumed that the participants would produce online writing on Facebook that is characterised by the presence of their own language, for instance, English, when they write for the Englishspeaking audience. We also assume that the participants would write on Facebook in Italian, if their addressees are Italian-native speakers. In other words, the hypothesis factors in the use of Facebook that involves producing public written statements that are influenced by multiple addressees concurrently with being embedded into social narratives afforded by the technology. By extending this assumption further, we argue that the participants become public personas on Facebook and, presumably, manage their profiles and Facebook statements (for instance, status updates) for multiple audiences. Consequently, the heterogeneity of audiences impacts upon the participants' linguistic choices.

However, we also hypothesise that writing on SNS is cognitively demanding (Stevenson, Schoonen and de Glopper 2006), since it involves the bilinguals' online management of their two languages in the SNS multimodal digital environment. Assuming that the cognitive costs of writing on SNS are exacerbated by such variables, as, for instance, mono- and bilingual audiences, it is not precluded that the participants' use of DMs would be subject to code-switching and/or 
code-mixing. Based upon the above hypothesis, our aims in this study are: 1) to identify DMs in the participants' status updates on Facebook; 2) to establish the frequencies of use of DMs in English and Italian, respectively, in the participants' status updates on Facebook in order to examine whether or not they are associated with English or Italian DMs, respectively, or both English and Italian DMs.

\subsection{Participants}

Three early balanced English/Italian bilinguals were recruited for the present case study. The participants (females, Mean age $=40,6$ y.o., standard deviation $=2,5$ ) were born in Australia in the families of Italian immigrants, who immigrated from Italy to Australia as young adults (between the age of 20 - 25). The participants indicated that they were fluent in both English and Italian before the age of five. The participants indicated that they used the Italian language at home when communicating with their parents in Australia. Additionally, they reported using predominantly Italian during their sojourns in Italy. The participants indicated that they had extended family members in Italy, who they visited at relatively regular intervals between one and two years within the last ten years. All participants resided in a large city in Australia. I knew the participants personally and made contact with them through social networks. To ensure confidentiality, the participants' real names were coded by means of the codes BLP 1, BLP 2, and BLP 3, respectively, where BL stands for bilingual and $\mathrm{P}$ for participant. The participants gave their consent to access their online writing on Facebook for research purposes, provided that all identifying data that involved names, locations, and other personal information would not be used in the illustrative examples in the article.

\subsection{Procedure}

The procedure in the study involved two main steps. First, the participants were asked to fill out a questionnaire involving their socio-linguistic background. The major findings of the questionnaire were summarised in the participants' description in section 2.1 above. In addition to the socio-linguistic data, the questionnaire consisted of questions associated with the participants' language proficiency in English and Italian, respectively. In accordance with Gollan et al. (2012: 594), the questionnaire consisted of questions indicating the bilinguals' self-ratings of the command of their two languages, where the participants were asked to rate their abilities in the English and Italian languages, respectively. Based upon previous studies (Gollan et al. 2012), the participants' self-ratings of their bilingual proficiency were deemed to be a reliable measure of their language proficiency. Following Hlavac (2006: 1873), no attempt was made to test proficiency in either English or Italian by means of the language tests. In accordance with Hlavac (2006), second generation of bilingual Australians reported a regular functional use of the English language in the most areas of life. The analysis of the socio- 
linguistic questionnaire under investigation yielded similar findings, concurrently with the use of Italian on a regular basis in several domains, for instance, work, home, and family life. Based upon the participants' self-ratings, and the methodology employed by Hlavac (2006), we found that the participants were functional, fluent, and competent users of English and Italian, respectively. After the participants filled out the questionnaire, I collected the participants' writing on Facebook in the form of their status updates written by the participants on Facebook within six months. Following Kapranov (2014) and Reershemius (2017), the period of time of six months was deemed sufficient and representative of the participants' writing on SNS. In addition, a post-hoc questionnaire was distributed to the participants after the data collection was completed (see Table 4 in section 2.5.1).

\subsection{Methods}

The methodology of data collection was based upon the methodological premises described by Reershemius (2017). Her data collection involved gathering screenbased and user-based data on Facebook. As regards the methodology of the DMs analysis I adopted a corpus-assisted method, since DMs were "usually studied from the vantage point of corpora analyses" (Fox Tree and Schrock 1999). The status updates on Facebook by each individual participant over the period of time of six months was collapsed into one file per participant (thus, making it three files in total) and analysed quantitatively using the WordSmith software (Scott 2008) in order to identify frequencies associated with the use of DMs in English and Italian, respectively. In addition to the quantitative analysis of DMs in WordSmith (Scott 2008), the present methodology involved a post-hoc qualitative analysis of the occurrences of DMs.

\subsection{The Corpus}

The corpus is comprised of 237 status updates on Facebook (Mean $=79$, standard deviation $=27$ ) that were written by the participants. The present research follows the definition of the status update on Facebook that was proposed by Page (2010), who indicates that status updates appear in the individual's profile in a standardised template and after being posted on Facebook are distributed into the news feeds of the user's friends (Page 2010: 425). Following Page (2010), status updates on Facebook are regarded in this research as an ongoing narrative of the user's life experiences (Page 2010: 425). The corpus of the participants' status updates consists of 4,287 words in total $($ Mean $=1429$, standard deviation $=522)$. The descriptive statistics of the corpus were calculated in the statistical program Statistical Package for Social Sciences (SPSS) and summarised in Table 1 below: 
Table 1. The Descriptive Statistics of the Corpus per Individual Participant

\begin{tabular}{|l|l|l|l|}
\hline \multicolumn{1}{|c|}{ Statistical Measure } & \multicolumn{1}{c|}{ BLP 1 } & \multicolumn{1}{c|}{ BLP 2 } & \multicolumn{1}{c|}{ BLP 3 } \\
\hline $\begin{array}{l}\text { Total N of FB status updates per par- } \\
\text { ticipant per 6 months }\end{array}$ & 79 & 112 & 46 \\
\hline $\begin{array}{l}\text { Total N of words in FB status up- } \\
\text { dates per participant per 6 months }\end{array}$ & 1841 & 1754 & 692 \\
\hline $\begin{array}{l}\text { Range of words in FB status updates } \\
\text { per participant per 6 months (mini- } \\
\text { mum) - (maximum) }\end{array}$ & $\begin{array}{l}1 \text { (min.) }-88 \\
\text { (max.) }\end{array}$ & $\begin{array}{l}1 \text { (min.) }-83 \\
(\max .)\end{array}$ & $\begin{array}{l}1 \text { (min.) }-50 \\
(\max .)\end{array}$ \\
\hline
\end{tabular}

Explanation of the abbreviations: $\mathrm{N}=$ number, $\mathrm{FB}=$ Facebook; BLP 1, BLP 2, BLP 3 = participants' codes

\subsection{Results and Discussion}

Table 2 below summarises the frequency of English and Italian DMs per 1000 per each individual participant.

Table 2. The Frequencies of DMs per 1000 Words in the Corpus per Individual Participant

\begin{tabular}{|c|c|c|c|c|}
\hline $\mathbf{N}$ & Discourse Marker (DM) & $\begin{array}{c}\text { Participant } \\
\text { BLP 1 }\end{array}$ & $\begin{array}{l}\text { Participant } \\
\text { BLP 2 }\end{array}$ & $\begin{array}{c}\text { Participant } \\
\text { BLP 3 }\end{array}$ \\
\hline 1. & And (Eng.) & $33(2,2 \%)$ & $56(3,2 \%)$ & $22(2,4 \%)$ \\
\hline 2. & As (Eng.) & $3(0,2 \%)$ & $4(0,2 \%)$ & - \\
\hline 3. & Because (Eng.) & - & $2(0,1 \%)$ & - \\
\hline 4. & But (Eng.) & $2(0,1 \%)$ & $7(0,4 \%)$ & $3(0,3 \%)$ \\
\hline 5. & Diciamo (It.) & $1(0,1 \%)$ & - & \\
\hline 6. & Ecco (It.) & - & $1(0,1 \%)$ & - \\
\hline 7. & Hmm (Eng.) & $1(0,1 \%)$ & $1(0,1 \%)$ & \\
\hline 8. & If (Eng.) & $2(0,1 \%)$ & - & $7(0,8 \%)$ \\
\hline 9. & Just (Eng.) & $1(0,1 \%)$ & $4(0,2 \%)$ & $4(0,4 \%)$ \\
\hline 10. & Ma (It.) & - & - & $1(0,1 \%)$ \\
\hline 11. & OK (Eng.) & - & $1(0,1 \%)$ & - \\
\hline 12. & Or (Eng.) & - & $5(0,3 \%)$ & $2(0,2 \%)$ \\
\hline 13. & Really (Eng.) & $3(0,2 \%)$ & $2(0,1 \%)$ & - \\
\hline 14. & So (Eng.) & $1(0,1 \%)$ & $6(0,3 \%)$ & $2(0,2 \%)$ \\
\hline 15. & \begin{tabular}{|l} 
Still (Eng.) \\
\end{tabular} & $3(0,2 \%)$ & - & - \\
\hline 16. & Then (Eng.) & - & - & $2(0,2 \%)$ \\
\hline 17. & Though (Eng.) & $1(0,1 \%)$ & $2(0,1 \%)$ & $1(0,1 \%)$ \\
\hline 18. & Well (Eng.) & $2(0,1 \%)$ & $4(0,2 \%)$ & - \\
\hline 19. & Wow (Eng.) & $1(0,1 \%)$ & $1(0,1 \%)$ & - \\
\hline 20. & Yep (Eng.) & $2(0,1 \%)$ & $1(0,1 \%)$ & $2(0,2 \%)$ \\
\hline
\end{tabular}

Explanation of the abbreviations: BLP 1, BLP 2, BLP 3 = participants' codes; Eng. = English; It. = Italian; $\mathrm{N}=$ number 
As seen in Table 2, 20 English and Italian DMs in total have been identified in the corpus. It is evident from Table 2 that the participants tend to employ English DMs (17 DMs out of 20), while the repertoire of the Italian DMs is limited (three DMs, such as diciamo, ecco, and $m a$ ). Each participants uses one Italian DM in their status updates they post on Facebook. In the next sub-sections, I will describe the use of the English and Italian DMs by the participants.

\subsubsection{The Use of the English DMs by the Participants}

As the data in Table 2 show, the participants use informal English DMs concurrently with stylistically neutral DMs. Following Rysová and Rysová (2018), neutral DMs can be in opposition to stylistically formal DMs (for example, the neutral DM thus and the formal DM herewith) and be used both in positive and negative contexts (Rysová and Rysová 2018: 24). Typically, the range of stylistically neutral DMs in the English language that can be used both in oral and written discourse involves DMs, such as and, because, if, just, etc. (Kapranov 2019). In this data set, all participants seem to use the following stylistically neutral English DMs: and, but, just, so, and though. In addition to the afore-mentioned DMs that are common to all the participants, such neutral English DMs are used by individual participants, as as (BLP 1 and BLP 2), because (BLP 2), if (BLP 1, BLP 3), or (BLP 2, BLP 3), really (BLP 1, BLP 2), and still (BLP 1), and then (BLP 3).

In terms of the most frequent English DMs, the results point to the participants' proclivity to use the stylistically neutral DMs. This tendency is illustrated by Figure 1 that summarises the accumulative use of the English DMs by the participants. Figure 1 is based upon the written data by the participants, where stylistically neutral and informal DMs in the English language have been presented per each individual participant, thus representing the frequency of use of stylistically neutral and informal DMs per 1000 words per participant.

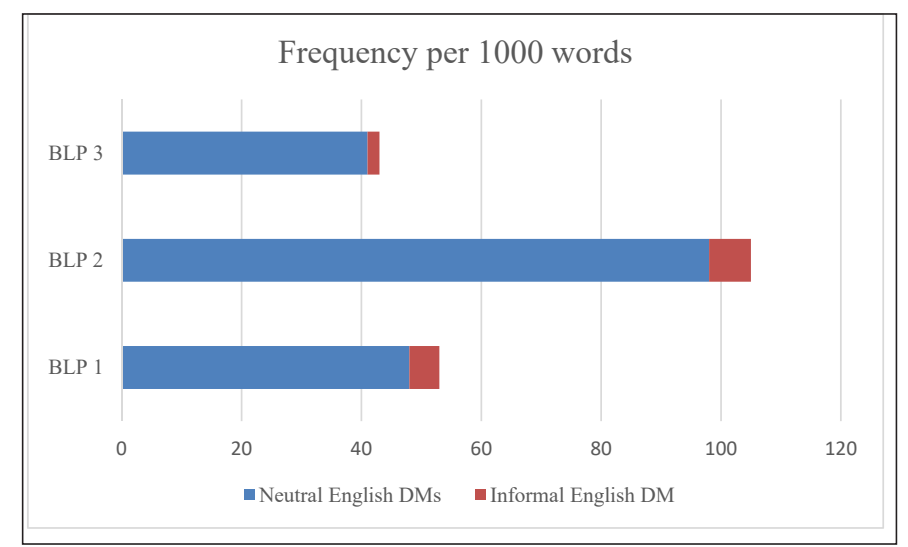

Figure 1. The Frequency of Stylistically Neutral and Informal English DMs per Participant per 1000 Words 
As seen in Figure 1, the participants' online writing on Facebook is characterised by a predominant use of stylistically neutral English DMs, while the informal DMs are substantially less numerous. Arguably, Figure 1 and Table 2 illustrate the participants' tendency to employ stylistically neutral DMs. Let us consider the use of the stylistically neutral DM so in examples (1) - (3) below:

(1) So today I got the bargain of the day. (BLP 1)

(2) So after an hour of searching I found my car parked outside ... (BLP 2)

(3) So, off to work (BLP 3)

These examples illustrate a typical use of the stylistically neutral English DM so that has been identified in online writing by all three participants. As evident from examples (1) - (3), all participants employ the DM so in order to introduce and summarise an event in their day lives, such as buying something at a reasonable price, finding the car eventually after having searched for it for a long time, and starting the day by going to work, respectively. Arguably, the use of the DM so in examples (1) - (3) would be indistinguishable from oral and written modes of discourse produced by any monolingual English L1 speaker. Presumably, these findings lend further support to the contention formulated by Sankoff et al. (1997), concerning DMs as "an accurate indicator of the extent to which a speaker is integrated into the local speech community" (Sankoff et al. 1997: 193). Given that all participants frequently use a set of English DMs, it can be assumed that their frequency could reflect the participants' proficiency in the English language. The assumption concerning the use of English DMs as an index of the English language proficiency is supported by previous research findings (Fox Tree 2010; Fox Tree and Schrock 1999), where informal English DMs in speech and in spontaneous writing have been discovered in English L1 monolinguals residing in the US. In particular, Fox Tree and Schrock (1999: 280) find a frequent use of DMs, such as well, I mean, like, and oh. Fox Tree (2010) indicates that similar informal DMs are often used by native speakers of English in unprepared, spontaneous writing. My results echo those of Fox Tree (2010) on the use of informal DMs in spontaneous writing. In particular, it is evident from Table 2 that the participants use informal DMs, such as $\mathrm{hmm}$ (used by BLP 1 and BLP 2, respectively), OK (BLP 2), well (BLP 1 and BLP 2, respectively), wow (BLP 1 and BLP 2, respectively), and yep (used by all three participants). It can be argued that the use of informal DMs by the participants in this study is reflective of their English languages competencies that are identical to English L1 speakers, given that English L1 monolingual speakers are likely to employ well, wow, or oh in their speech as well as in informal writing (Fox Tree 2015).

The post-hoc qualitative analysis of the data was conducted in order to examine the qualitative types of DMs in accordance with the classification of DMs proposed by Fraser $(1999 ; 2015)$. The results of the qualitative analysis indicate 
that the DMs in the present corpus are comprised of the following types, e.g. i) contrastive, ii) elaborative, iii) implicative, and iv) temporal. The types of DMs both in the English and Italian languages are summarised in Table 3 below.

Table 3. The Qualitative Types of English and Italian DMs in the Corpus per Participant

\begin{tabular}{|c|c|c|c|c|c|}
\hline $\mathbf{N}$ & Participants & $\begin{array}{c}\text { Contrastive } \\
\text { DMs }\end{array}$ & $\begin{array}{c}\text { Elaborative } \\
\text { DMs }\end{array}$ & $\begin{array}{c}\text { Implicative } \\
\text { DMs }\end{array}$ & $\begin{array}{c}\text { Temporal } \\
\text { DMs }\end{array}$ \\
\hline 1 & BLP1 & $\begin{array}{l}\text { But } \\
\text { Still } \\
\text { Though }\end{array}$ & $\begin{array}{l}\text { And } \\
\text { As } \\
\text { Diciamo } \\
\text { Really } \\
\text { Yep } \\
\end{array}$ & \begin{tabular}{|l|l} 
Hmm \\
If \\
So \\
Well \\
Wow \\
\end{tabular} & \begin{tabular}{|l} 
Just \\
\end{tabular} \\
\hline 2 & BLP 2 & $\begin{array}{l}\text { But } \\
\text { Or } \\
\text { Though }\end{array}$ & $\begin{array}{l}\text { And } \\
\text { As } \\
\text { OK } \\
\text { Really } \\
\text { Yep }\end{array}$ & \begin{tabular}{|l} 
Because \\
Ecco \\
Hmm \\
So \\
Well \\
Wow \\
\end{tabular} & Just \\
\hline 3 & BLP 3 & $\begin{array}{l}\text { But } \\
\text { Ma } \\
\text { Or } \\
\text { Though }\end{array}$ & $\begin{array}{l}\text { And } \\
\text { Yep }\end{array}$ & \begin{tabular}{|l|} 
So \\
Then
\end{tabular} & Just \\
\hline
\end{tabular}

It is evident from the data presented in Table 3 that the elaborative DMs in English and Italian appear to be substantially represented, whereas the temporal type of DMs is underused by the participants. Figure 2 below illustrates this observation. Figure 2 involves the total sum of occurrences of DMs per 1000 words per participant in accordance with the aforementioned qualitative types of DMs in English and Italian.

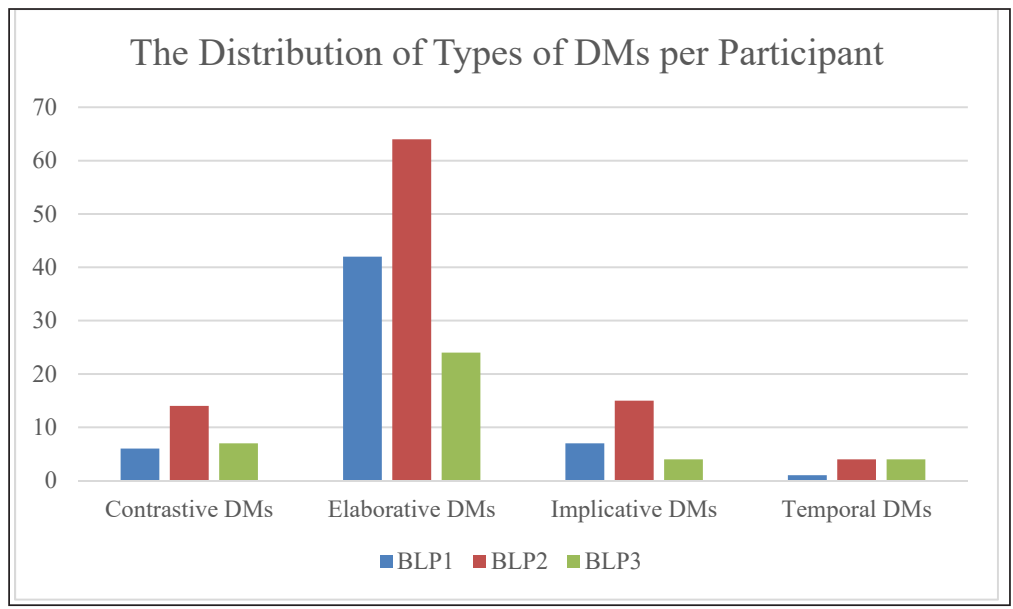

Figure 2. The Distribution of the Qualitative Types of DMs per Participant 
As illustrated by Figure 2 and Table 3, the elaborative DMs appear to be qualitatively and quantitatively well represented. Specifically, there are 42 elaborative DMs in total in the status updates written by the participant BLP 1, 64 elaborative DMs in the writing by BLP 2, and 24 elaborative DMs in total in the writing by BLP 3. The participants' predominant use of elaborative DMs in English and Italian could be explained by a descriptive nature of the Facebook status updates writing. As indicated by Page (2010), status updates on Facebook seem to adhere to the personal narrative style that reflects everyday routines of an individual. The data in this study support the observation made by Page (2010) in the sense that the status updates consist of descriptions of everyday events, including the weather, the participants' mood, their travel, leisure activities, and domestic chores (Page 2010: 426). The participants' status updates as mini-narratives typically involve a certain elaboration of ideas. Arguably, the elaboration of ideas presupposes the use of elaborative DMs that reflect this relationship in the mininarrative. To illustrate this finding, let us consider the following status update written by the participant BLP 2, e.g. "More rain! And there's worse to come tomorrow". In this status update, which provides a mini-narrative of the weather report, the participant communicates the weather forecast (e.g., "More rain!") and elaborates upon it by adding the next sentence that starts with the elaborative DM and, e.g. "And there's worse to come tomorrow" (BLP 2).

Unlike the elaborative DMs used by the participants, the contrastive DMs appear to be less numerous in the participants' status updates, e.g. BLP 1 uses 6 contrastive DMs over the total observation period, whereas 14 contrastive DMs are found on BLP2's status updates and 7 contrastive DMs are employed by BLP 3. Whereas the contrastive DMs are used by the participants within the discursive space of mini-narratives that reflect their everyday routines, these DMs seem to signal that "there is a sense of dissonance" (Fraser 1988: 30; Povolná 2012). For instance, when the participant BLP 3 writes about going out to see a film with the actor Russell Crowe, she indicates that "I'm not a fan. But giddy up anyways" (BLP 3). As seen in this status update that involves the participant's pastime event, the dissonance in the sense expressed by Fraser (1988) is associated with the use of the contrastive DM but. This contrastive DM is pragmatically employed in the mini-narrative to convey the idea that whereas the participant does not consider herself a fan of Russell Crowe, she, nevertheless, intends to see the recent film where the actor stars.

Similarly to the group of contrastive DMs, the implicative DMs in the participants' status updates are less numerous than the elaborative DMs. The implicative DMs in the corpus are represented by 7 DMs in the status updates by BLP 1, 15 DMs by BLP 2, and 4 DMs by BLP 3. Let us examine the participant BLP1's status update with the implicative DM so, e.g. "So today I got the bargain of the day" (BLP 1). Following Fraser (2015), the implicative DM so in the aforementioned status update could be taken to indicate a mini-narrative that involves a certain continuation of the situation with the bargain. For instance, the bargain may imply that the participant is satisfied with it, or, alternatively, another possible scenario with the 
implicative DM so might involve an implication that is associated with the suggestion to other Facebook friends to make a similar purchase at a discounted price.

In contrast to the previously discussed three types of DMs, e.g. elaborative, contrastive, and implicative, the group of temporal DMs is under-represented in the corpus of the participants' status updates. Specifically, BLP1 uses 1 temporal DM, whereas BLP 2 and BLP 3 employ 4 temporal DMs each. Notably, all participants use the temporal DM just, which, according to Fraser (1999), signals that an event is temporally related to the piece of discourse in the preceding sentence (Fraser 1999). For example, the participant BLP 2 writes in her status update about a pump that was needed after heavy rainfall and proceeds by indicating that "Just went to the nearest Bunnings Warehouse (BLP 2). As evident from the afore-mentioned quote, the temporality associated with the DM just is related to the preceding description of the heavy rain on that day and the need to purchase a pump so that in the next sentence the DM just links it to the participant's going to the retail chain Bunnings Warehouse in order to buy the pump.

\subsubsection{The Use of the Italian DMs by the Participants}

While the participants use a range of qualitatively different English DMs, they employ a limited repertoire of the Italian DMs. Specifically, each of the participants uses only one Italian DM in their status update writing on Facebook within the period of time of six months. These DMs are diciamo (used by BLP 1), ecco (employed by BLP 2), and $m a$ (identified in the writing by BLP 3). In terms of the style conventions of the Italian language, the DMs diciamo, ecco, and $m a$ are deemed to pertain to stylistically neutral DMs (Bazzanella et al. 2007). It should be noted that unlike the English DMs used by the participants, for instance, the temporal DM just, there are no DMs that are common to all three participants. Examples (4) - (6) illustrate the contextual background of these DMs:

(4) Diciamo cosi ... questi cannoli sono perfetti. (English: Let's say that these cannoli are perfect) (BLP 1)

(5) Ecco, sei bravo bello! (English: Well, good on you, handsome!) (BLP 2)

(6) Ma vaffanculo! (English: But piss off!) (BLP3)

In (4), the participant writes her status update while enjoying her sojourn to Italy. The evidence of her stay in Italy is provided by the participant herself, who indicates it by marking a location in Italy on her status update. The participant writes that she is staying with the extended family and comments about cannoli, Italian pastries. The DM diciamo (English: let's say) is used within the whole sentence written in Italian. Presumably, the participant's stay in Italy facilitates the writing of the Facebook in Italian. Another possible explanation of the use of Italian in (4) is associated with the participant's audience. Arguably, the participant aims at 
addressing an Italian-speaking audience, for instance Facebook friends, who are either Italians residing in Italy, or Italian-speaking Australians.

Examples (5) and (6,) respectively, are written by the participants in Australia. In (5), the participant writes a short text about her male cousin, who is an Italian Australian. It could be assumed that the participant's message in the Italian language reflects the participant's proximity to the addressee in terms of the social distance and signals ethno-linguistic affiliation with the addressee or, possibly, with a group of Italian-speaking addressees. In (6) the participant writes about a day out at a winery outside of Melbourne and describes excessive drinking and eating that compromises her diet. Set against the background of a family weekend out at the winery, the participant composes her status update on Facebook by resorting to the Italian language, which is understood by her family and, presumably, by some of her Facebook friends, who are either Italian-Australians or Italians residing permanently in Italy. The common denominator of the Italian DMs used in (4) - (6) involves Italian-speaking addressees, who are either in Italy, as seen in (4), or in Australia. It can be assumed that all participants are aware of the communicative purpose of choosing the Italian language in the writing of status updates on Facebook. Aiming at the Italian-speaking addressees, the participants resort to Italian and employ DMs that would typically be used by Italian L1 speakers and/or other English/Italian bilinguals. This assumption is further supported by the post-hoc questionnaire that involves questions associated with the language use on Facebook by the participants. The post-hoc questionnaire is summarised in Table 4 below:

Table 4. The Post-Hoc Questionnaire with the Participants Concerning Their Language Choices on Facebook

\begin{tabular}{|c|l|l|}
\hline $\mathbf{N}$ & \multicolumn{1}{|c|}{ Questions in the Post-Hoc Questionnaire } & The Participants' Answers \\
\hline 1. & $\begin{array}{l}\text { Are you aware of the choice of the language you } \\
\text { use in writing your status updates on Facebook? } \\
\text { Please, answer YES, NO, or NOT SURE }\end{array}$ & $66,6 \%$ YES \\
$33,3 \%$ NOT SURE \\
\hline 2. & $\begin{array}{l}\text { When you write your status updates on Face- } \\
\text { book, do you consider the people (your Facebook } \\
\text { friends and/or followers) you are writing for? } \\
\text { Please, answer YES, NO, or NOT SURE }\end{array}$ & $100 \%$ YES \\
\hline 3. & $\begin{array}{l}\text { When you write your status updates on Facebook, } \\
\text { do you consider the language that the people who } \\
\text { you are writing for speak? Please, answer YES, } \\
\text { NO, or NOT SURE }\end{array}$ & \\
\hline 4. & $\begin{array}{l}\text { Which language would you use in writing your } \\
\text { status updates when you are in Australia? }\end{array}$ & English and Italian $100 \%$ \\
\hline 5. & $\begin{array}{l}\text { Which language would you use in writing your } \\
\text { status updates when you are in Italy? }\end{array}$ & English and Italian $100 \%$ \\
\hline
\end{tabular}


It follows from Table 4 that the participants' awareness of their audience, in these cases, Italian-speaking addressees, maps onto their choice of the Italian language and the micro-discursive elements, such as Italian DMs. Arguably, these findings lend further support to the observation by Foursha-Stevenson and Nicoladis (2011: 522), who argue that "bilinguals have extensive experience choosing the appropriate language for the context." Presumably, the afore-mentioned DMs are deemed to be appropriate micro-discursive means in those communicative situations that involve Italian speakers irrespective whether or not the Italian-speaking audience is physically located in Italy and/or Australia.

\section{Conclusions}

This article involves a case study that examines the use of DMs by early balanced English/Italian bilinguals in their writing of status updates on Facebook. The case study contributes to a growing body of research on SNS and on writing practices by bilingual individuals. Arguably, the focus on new media ideologies and SNS practices is highly relevant, since SNS form an inseparable part of everyday routines of a substantial number of bilingual individuals. Seen from the vantage point of the present journal volume, the study addresses the English language and Anglophone contexts with respect to communicative practices by bilingual individuals in SNS environments.

Judging from the findings in the present case study, it can be concluded that the participants predominantly use English DMs. The English DMs employed by the participants can be further classified into two categories in accordance with the notion of style of the English language, in particular, stylistically informal DMs (for example, yep), and stylistically neutral DMs, such as so. The analysis of the findings has revealed that the participants exhibit preferences for the stylistically neutral English DMs, such as and, as, but, etc. Amongst the qualitative types of DMs the participants appear to employ elaborative DMs whose use is determined, arguably, by the descriptive character of the participants' status updates that involve mini-narratives of their everyday routines.

In addition to the English DMs, the participants use Italian DMs in those limited instances when they address the Italian-speaking audience, when the participants are either in Italy, or in a family-related episode in Australia. It has been found that the Italian DMs are used in grammatically appropriate Italian sentences that seem to be pragmatically correct in the context of SNS writing. This observation could be taken to lend indirect support to the prior studies (for instance, Sankoff et al. 1997) that point to a correlation between a bilingual's language proficiency and the appropriate use of DMs in the bilingual's two languages. Given that the participants appear to construct their status updates on Facebook by making relevant socio-cultural and linguistic choices, we suggest that their writing on Facebook is characterised by strategic code-switching in the sense of the term proposed by Gort (2006: 325). Strategic code-switching is exemplified in the pre- 
sent findings by those instances, when the participants employ full-formed Italian sentences that involve Italian DMs in order to address Italian-speaking audience irrespective of whether or not the audience is physically located in Italy.

Strategic code-switching could be, presumably, explained by the bilinguals' inhibition of their another language, in this case English, in order to produce written output in Italian. Arguably, the mechanism of inhibition is present in each of the components of the model of writing proposed by Chenoweth and Hayes (2001), namely the Proposer, the Translator, the Transcriber, and the Reviser. While the present data are focused upon the analysis of the final product of writing, and not as a process thereof, it is beyond the scope of this case study to offer robust generalisations concerning the interface of the bilinguals' inhibitory mechanism with the components of the model of writing formulated by Chenoweth and Hayes (2001). Arguably, the inhibitory mechanism should be activated at the Proposer mode, since the participants in this case study seem to be aware of the addressees of their messages and the addressees' language. This assumption appears to be supported by the results of the post-hoc questionnaire (see Table 4) which indicates that all participants are aware of their audience and the language choices to be made in order to address the audience. Supposedly, this awareness maps onto the participants' choice of one of their languages in the composition of a status update on Facebook aimed at the members of a specific linguistic community, be it the English-speaking community in Australia, or Italian speakers in Italy and in Australia.

Obviously, the present findings should be regarded with caution, since this case study involves a limited number of participants. Amongst other shortcomings of the case study one should observe that it focuses on the DMs as the final product of writing and not as a process thereof. Arguably, further avenues of research involving the use of DMs by early balanced bilinguals should explore the components of the writing process rather than the final product. However, this case study offers some insight into online writing by early balanced bilinguals. Given that the majority of studies involving DMs used by bilinguals address oral discourse, this study can serve as an exploratory endeavour into the use of DMs by bilinguals in writing, specifically in writing on SNS. Another possible direction in future research should involve a focus on the process of writing by bilinguals. That direction might involve the application of the Think-Aloud protocols (TAPs) that might help elucidate the linguistic choices made by bilinguals in SNS digital environments.

\section{Acknowledgements}

I want to express my appreciation of the participants in the study. Their input is invaluable. I want to acknowledge research funding provided by Western Norway University of Applied Sciences (Norway). 


\section{References}

Andersen, Elaine S., Maquela Brizuela, Beatrice DuPuy and Laura Gonnerman (1999) Cross-linguistic evidence for the early acquisition of discourse markers as register variables. Journal of Pragmatics 31 (10), 1339-1351.

Androutsopoulos, Jannis (2015) Networked multilingualism: Some language practices on Facebook and their implications. International Journal of Bilingualism 19 (2), 185-205.

Androutsopoulos, Jannis (2014) Moments of sharing: Entextualization and linguistic repertoires in social networking. Journal of Pragmatics 73, 4-18.

Ardila, Alfredo, Krystal Garcia, Melissa Garcia, Joselyn Mejia and Grace Vado (2017) Writing and reading knowledge of Spanish/English second-generation bilinguals. Reading and Writing 30(2), 387-400.

Bazzanella, Carla, Cristina Bosco, Alessandro Garcea, Barbara G. Fivela, Johanna Miecznikowski and Francesca T. Brunozzi (2007) Italian allora, French alors: Functions, convergences and divergences. Catalan Journal of Linguistics, 6 (1), 9-30.

Blommaert, Jan, James Collins and Stef Slembrouck (2005) Spaces of multilingualism. Language \& Communication 25 (3), 197-216.

Bongartz, Christiane and Jacopo Torregrossa (2017) The effects of balanced biliteracy on GreekGerman bilingual children's secondary discourse ability. International Journal of Bilingual Education and Bilingualism 1, 1-16.

Chenoweth, Anne N. and John R. Hayes (2001) Fluency in writing: Generating text in L1 and L2. Written Communication 18 (1), 80-98.

Christiansen, M. Sidury (2018) ‘ $i$ Hable Bien M'ijo o Gringo o Mx!’: language ideologies in the digital communication practices of transnational Mexican bilinguals. International Journal of Bilingual Education and Bilingualism 21 (4), 439-450.

Cieślicka, Anna B. (2015) Idiom acquisition and processing by second/foreign language learners. In Heredia, R. R. and Cieślicka, A. B. (Eds.) Bilingual figurative language processing. Cambridge: Cambridge University Press, 208-244.

Dailey-O'Cain, Jennifer and Grit Liebscher (2006) Language learners' use of discourse markers as evidence for a mixed code. International Journal of Bilingualism 10 (1), 89-109.

de la Luz Reyes, Maria (2012) Spontaneous Biliteracy: Examining Latino Students' Untapped Potential. Theory Into Practice 51 (4), 248-255.

Dunn, Alexandra L. and Jean E. Fox Tree (2009) A quick, gradient bilingual dominance scale. Bilingualism: Language and Cognition 12 (3), 273-289.

Flores-Ferrán, Nydia (2014) So pues entonces: An examination of bilingual discourse markers in Spanish oral narratives of personal experience of New York City-born Puerto Ricans. Sociolinguistic Studies 8 (1), 57.

Foursha-Stevenson, Cassandra and Elena Nicoladis (2011) Early emergence of syntactic awareness and cross-linguistic influence in bilingual children's judgments. International Journal of Bilingualism 15 (4), 521-534.

Fox Tree, Jean E. (2015) Discourse markers in writing. Discourse Studies 17 (1), 64-82.

Fox Tree, Jean E. (2010) Discourse markers across speakers and settings. Language and Linguistics Compass 4 (5), 269-281.

Fox Tree, Jean E. (2000) Spontaneous talk. In: Linda Wheeldon (ed.) Aspects of language production. New York: Taylor and Francis, 375-404.

Fox Tree, Jean E. and Josef C. Schrock (1999) Discourse markers in spontaneous speech: Oh what a difference an oh makes. Journal of Memory and Language 40 (2), 280-295.

Francis, Norbert (2005) Bilingual children's writing: Self-correction and revision of written narratives in Spanish and Nahuatl. Linguistics and Education 16 (1), 74-92.

Fraser, Bruce (2015) The combining of Discourse Markers - A beginning. Journal of Pragmatics $86,48-53$.

Fraser, Bruce (1999) What are discourse markers?. Journal of Pragmatics 31 (7), 931-952. 
Fraser, Bruce (1988) Types of English discourse markers. Acta Linguistica Hungarica 38 (1-4), 19-33.

Fuller, Janet M. (2001) The principle of pragmatic detachability in borrowing: English-origin discourse markers in Pennsylvania German. Linguistics 39 (2), 351-370.

Fung, Loretta and Ronald Carter (2007) Discourse markers and spoken English: Native and learner use in pedagogic settings. Applied Linguistics 28 (3), 410-439.

Gollan, Tamar H., Gali H. Weissberger, Elin Runnqvist, Rosa I. Montoya and Cynthia C. Cera (2012) Self-ratings of spoken language dominance: A Multilingual Naming Test (MINT) and preliminary norms for young and aging Spanish-English bilinguals. Bilingualism: Language and Cognition 15 (3), 594-615.

Gort, Mileidis (2006) Strategic codeswitching, interliteracy, and other phenomena of emergent bilingual writing: Lessons from first grade dual language classrooms. Journal of Early Childhood Literacy 6 (3), 323-354.

Goss, Emily L. and Joseph C. Salmons (2000) The evolution of a Bilingual Discourse Marking System: Modal particles and English markers in German-American dialects. International Journal of Bilingualism 4 (4), 469-484.

Green, David W. (1998) Mental control of the bilingual lexico-semantic system. Bilingualism: Language and cognition 1 (2), 67-81.

Grosjean, François (2010) Bilingual. Life and Reality. Cambridge, Massachusetts: Harvard University Press.

Grosjean, François (1994) Individual bilingualism. The Encyclopedia of Language and Linguistics $3,1656-1660$.

Heine, Bernd (2013) On discourse markers: Grammaticalization, pragmaticalization, or something else? Linguistics 51 (6), 1205-1247.

Heredia, Roberto R. and Jeanette Altarriba (2001) Bilingual language mixing: Why do bilinguals code-switch?. Current Directions in Psychological Science 10 (5), 164-168.

Heredia, Roberto R. and Anna B. Cieślicka (2014) Bilingual memory storage: Compound-coordinate and derivatives. In: Roberto R. Heredia and Jeanette Altarriba (eds.), Foundations of bilingual memory. New York: Springer, 11-39.

Hlavac, Jim (2006) Bilingual discourse markers: Evidence from Croatian-English code-switching. Journal of Pragmatics 38 (11), 1870-1900.

Kapranov, Oleksandr (2014) Syntactic performance in online written discourse by an English/ Swedish bilingual with Asperger's syndrome: A Case Study. East European Journal of Psycholinguistics 1 (1), 74-80.

Kapranov, Oleksandr (2019) Discourse markers in the novice translator students' translations from Swedish into English. In: Michal Organ (ed.), Translation Today: Applied Translation Studies in Focus. Berlin: Peter Lang, 63-80.

MacSwan, Jeff (2008) Code switching and grammatical theory. In: Tej K, Bhatia and William Ritchie (eds.) The Handbook of Bilingualism. UK: Wiley-Blackwell, 282-311.

Majchrzak, Olga (2017) Learner Identity and Learner Beliefs in EFL Writing. Switzerland: Springer.

Maschler, Yael (2000) Toward fused lects: Discourse markers in Hebrew English bilingual conversation twelve years later. International Journal of Bilingualism 4 (4), 529-561.

Maschler, Yael and Deborah Schiffrin (2015) Discourse markers: Language, meaning, and context. The Handbook of Discourse Analysis 2, 189-221.

Matras, Yaron (2000) Fusion and the cognitive basis for bilingual discourse markers. International Journal of Bilingualism 4 (4), 505-528.

Meisel, Juergen M. (2007) The weaker language in early child bilingualism: Acquiring a first language as a second language?. Applied Psycholinguistics 28 (3), 495-514.

Nicoladis, Elena (2006) Cross-linguistic transfer in adjective-noun strings by preschool bilingual children. Bilingualism: Language and Cognition 9 (1), 15-32.

Olshtain, Elite and Shoshana Blum-Kulka (1989) Happy Hebrish: Mixing and switching in American Israeli family interaction. In: Susan Gass et al. (eds.), Variation in Second Language Acquisition. Clevedon: Multilingual Matters, 59-83. 
Orsolini, Margherita (1993) Because in children's discourse. Applied Psycholinguistics 14 (1), 89-120.

Paculanang, Maria Dolores (2018) Code-switching and discourse markers: The case of the anxious Cebuano-Visayan teacher-interns. Prism 22 (2), 1-28.

Page, Ruth (2010) Re-examining narrativity: Small stories in status updates. Text \& Talk. An Interdisciplinary Journal of Language, Discourse \& Communication Studies 30 (4), 423-444.

Pérez-Sabater, Carmen and Ginette Maguelouk Moffo (2019) Managing identity in football communities on Facebook: Language preference and language mixing strategies. Lingua. https:// www.sciencedirect.com/science/article/pii/S0024384118303905.

Povolná, Renata (2012) Casual and contrastive discourse markers in novice academic writing. Brno Studies in English 38 (2), 131-148.

Reershemius, Gertrud (2017) Autochthonous heritage languages and social media: writing and bilingual practices in Low German on Facebook. Journal of Multilingual and Multicultural Development 38 (1), 35-49.

Riley, Jacqueline (2015) Bilingual Facebook users' cognitive writing processes. Canadian Journal of Learning \& Technology 41 (1), 1-17.

Rysová, Magdalena and Kateřina Rysová (2018) Primary and secondary discourse connectives: Constraints and preferences. Journal of Pragmatics 130, 16-32.

Sankoff, Gillian, Pierette Thibault, Naomi Nagy, Helene Blondeau, Marie-Odile Fonollosa and Lucie Gagnon (1997) Variation in the use of discourse markers in a language contact situation. Language Variation and Change 9 (2), 191-217.

Schiffrin, Deborah (1987) Discourse Markers. Cambridge: Cambridge University Press.

Scott, Mike (2008) WordSmith tools version 5. Liverpool: Lexical Analysis Software 122.

SPSS (2009) Statistical Package for the Social Sciences. A software program by IBM

Stevenson, Marie, Rob Schoonen and Kees de Glopper (2006) Revising in two languages: A multidimensional comparison of online writing revisions in L1 and FL. Journal of Second Language Writing 15 (3), 201-233.

Tao, Lily, Anna Marzecová, Marcus Taft, Dariusz Asanowicz and Zofia Wodniecka (2011) The efficiency of attentional networks in early and late bilinguals: the role of age of acquisition. Frontiers in Psychology 2, 1-19.

Torres, Lourdes (2002) Bilingual discourse markers in Puerto Rican Spanish. Language in Society $31(1), 65-83$.

Trillo, Jesus Romero (2002) The pragmatic fossilization of discourse markers in non-native speakers of English. Journal of Pragmatics 34 (6), 769-784.

Van der Linden, Lize, Laurence Dricot, Miet De Letter, Wouter Duyck, Marie-Pierre de Partz, Adrian Ivanoiu and Arnaud Szmalec (2018) A case study about the interplay between language control and cognitive abilities in bilingual differential aphasia: Behavioral and brain correlates. Journal of Neurolinguistics 46, 37-68.

Waltereit, Richard (2006) The rise of discourse markers in Italian: a specific type of language change. Approaches to Discourse Particles 1, 61-76.

Wang, Xin (2013) Language dominance in translation priming: Evidence from balanced and unbalanced Chinese-English bilinguals. Quarterly Journal of Experimental Psychology 66 (4), 727-743.

Yang, Sujin, Hwajin Yang and Andree Hartanto (2019) The effects of script variation, literacy skills, and immersion experience on executive attention: A comparison of matched monoscriptal and biscriptal bilinguals. Bilingualism: Language and Cognition 22 (1), 142-156.

Yow, Quin W. and Xiaoqian Li (2015) Balanced bilingualism and early age of second language acquisition as the underlying mechanisms of a bilingual executive control advantage: why variations in bilingual experiences matter. Frontiers in Psychology 6, 1-12. 
OLEKSANDR KAPRANOV is an associate professor at the Department of Language, Mathematics, and Interpreting of Western Norway University of Applied Sciences, Norway. His research interests involve academic writing, cognitive linguistics, and psycholinguistics. After the completion of his $\mathrm{PhD}$ at The University of Western Australia in Perth (WA), Oleksandr was a post-doctoral researcher at Lund University (Sweden) and at The University of Bergen (Norway), respectively. He has published over 40 research articles in peer-reviewed journals. His book chapters have recently been published by Cambridge Scholars Publishing, Peter Lang, Routledge, and Springer.

Address: Oleksandr Kapranov, Department of Language, Literature, Mathematics and Interpreting, Western Norway University of Applied Sciences, campus Haugesund/Stord, Bjørnsonsgate 45, 5528 Haugesund, Norway. [email: Oleksandr.Kapranov@hvl.no] 